\title{
The Structural and the Magnetic Properties of Aluminum Substituted Yttrium Iron Garnet
}

\author{
Qassem I. Mohaidat *, Mahdi Lataifeh ${ }^{a}$, Khozima Hamasha ${ }^{b}$,Sami H. Mahmood Ibrahim Bsoul $^{d}$, \\ Mufeed Awawdeh ${ }^{a, e}$ \\ aPhysics Department, Yarmouk University, Irbid 21163, Jordan \\ ${ }^{b}$ Department of Basic Sciences, Al-Huson University College, Al-Balqa Applied University, Irbid, Jordan \\ ${ }^{c}$ Physics Department, The University of Jordan, Amman 11942, Jordan \\ ${ }^{d}$ Physics Department, Al al-Bayt University, Mafraq 13040, Jordan \\ ${ }^{e}$ College of Science and Health Professions, King Saud Bin Abdulaziz University for Health Sciences, Jeddah,
} Saudi Arabia

Received: September 06, 2017; Revised: December 30, 2017; Accepted: February 17, 2018

In this paper, $\mathrm{Y}_{3} \mathrm{Al}_{x} \mathrm{Fe}_{5-x} \mathrm{O}_{12}$ powders with $x=0.0,0.2,0.4,0.6,0.8$, and 1.0 were prepared via solid state reaction method. X-ray diffraction, Vibrating Sample Magnetometry, and Mössbauer Spectroscopy were used to study their structural and magnetic properties. The XRD patterns of the samples show single phase structure with decreasing lattice constant when increasing Al concentration. The saturation magnetization decreases from 28.0 to $10.1 \mathrm{emu} / \mathrm{g}$ with increasing $\mathrm{Al}^{3+}$ from 0.0 to 1.0 due to the reduction of the superexchange interactions between iron ions in the $a$ and $d$ sublattices. Room temperature Mössbauer spectra for the samples were collected and analyzed. The hyperfine field values for octahedral and tetrahedral sites of the samples decreased with increasing Al concentration. Moreover, Mössbauer results have shown that $\mathrm{Al}^{3+}$ ions prefer to replace $\mathrm{Fe}^{+3}$ at the octahedral sites.

Keywords: Mössbauer Spectroscopy, Hyperfine Interactions, Magnetic Properties, X-ray Diffraction.

\section{Introduction}

Yttrium iron garnet (YIG) has received intensive studies since its discovery in $1956^{1}$. YIG and substituted YIG provide remarkable performance in microwave devices due to their tunable magnetization and low dielectric losses ${ }^{2,3}$. The magnetic properties of YIG with chemical composition $\left\{\mathrm{Y}_{3}{ }^{3+}\right\}_{c}\left[\mathrm{Fe}_{2}{ }^{3+}\right]_{a}\left(\mathrm{Fe}_{3}{ }^{3+}\right)_{d} \mathrm{O}_{12}{ }^{2-}$, where $\mathrm{Y}^{3+}$ ions occupy dodecahedral sites and magnetic $\mathrm{Fe}^{3+}$ ions occupy octahedral [ $a$-sublattice] and tetrahedral ( $d$-sublattice) sites, are determined by the strength of the superexchange interactions between magnetic ions in the various sublattices ${ }^{4-7}$. Accordingly, the substitution of $\mathrm{Y}^{3+}$ ions by other rare earth ions, and/or $\mathrm{Fe}^{3+}$ ions by nonmagnetic ions were adopted for successful modification of the magnetic properties of YIG for potential technological applications ${ }^{3}$.

Garnets were functionalized in either the form of bulk materials for microwave passive devices, or in the form of thin films for magnetic-bubble-type digital memories. Although the magnetization of the garnet films for bubbles is essentially the same as in the bulk state, the magnetic anisotropy of the films is quite different, depending on the characteristics of the films, and their synthesis routes. For details on the parameters of bubbles which play an important role in solid state device applications, and the relation of these parameters to the magnetic and physical characteristics of the films, the reader is referred to the review article by Eschenfelder ${ }^{8}$.
The replacement of $\mathrm{Fe}^{3+}$ magnetic ions with non-magnetic ions such as $\mathrm{Al}^{3+}$ has caught the attention of many researchers. The site selectivity of $\mathrm{Al}^{3+}$ ions in Al-substituted YIG was first reported by Gilleo and Geller in $1958^{9,10}$, where it was found that $\mathrm{Al}^{3+}$ ions substitute $\mathrm{Fe}^{3+}$ ions preferentially at the tetrahedral $(d)$ sites. In later detailed studies of the crystal chemistry of garnets, it was reported that the fraction of $\mathrm{Al}^{3+}$ ions at the tetrahedral sites decreased smoothly with the increase of Al concentration from 1.0 at $x=0$ to 0.6 at $x=5^{11,12}$. In addition, Cohen and Chegwidden (1966) concluded from their magnetization data that the $\mathrm{Al}^{3+}$ ions redistributed themselves among tetrahedral and octahedral sites with the increase of the temperature at which the garnet was heat treated ${ }^{13}$. In a more recent study, Kim et al. have investigated the magnetic and structural properties of the substituted $\mathrm{Y}_{3} \mathrm{Fe}_{5-x} \mathrm{Al}_{x} \mathrm{O}_{12}(x=0.0,0.25,0.50,0.75$, and 1.0) garnets prepared by sol-gel method. In their study, both the lattice constant $a$ and the saturation magnetization $M_{s}$ decreased with increasing Al concentration. Moreover, room temperature (RT) Mössbauer spectra reflect cation distribution of $\mathrm{Fe}^{3+}$ and $\mathrm{Al}^{3+}$ at tetrahedral sites where six components were used to fit the sample with $x=1^{14}$.

Thongmee et al. have reported the hyperfine parameters and the saturation magnetization of the system $\mathrm{Y}_{3} \mathrm{Fe}_{5-x} \mathrm{Al}_{x} \mathrm{O}_{12}$ $(0<x<1$ and $x=1.5,2.0$, and 2.5). It was shown that the 
saturation magnetization decreased with $\mathrm{Al}^{3+}$ substitution for $\mathrm{Fe}^{3+}$. In addition, RT Mössbauer spectra for the samples with $0 \leq x \leq 0.8$ were fitted with three magnetic components, two corresponding to octahedral sites and one to tetrahedral $\operatorname{sites}^{15}$. On the other hand, Motlagh et al. have shown that a systematic line broadening was observed in the Mössbauer spectra with the increase of $\mathrm{Al}^{3+}$ concentration, which can be attributed to the presence of hyperfine field distribution because of the random distribution of $\mathrm{Al}^{3+}$ in the octahedral and tetrahedral sites ${ }^{16}$.

Based on the previous studies, aluminum-substituted iron in YIG were synthesized by different methods such as sol-gel $\operatorname{method}^{14,17,18}$, co-precipitation method ${ }^{19}$, and ball milling ${ }^{16}$. Mössbauer spectra for synthesized garnets were fitted with different numbers of components corresponding to $\mathrm{Fe}^{3+}$ in octahedral and tetrahedral sites. The results of the previous studies indicated that the site selectivity of $\mathrm{Al}^{3+}$ ions may be sensitive to the preparation method, heat treatment, and the level of Al substitution. In the present study, investigation of the structural, magnetic, and hyperfine interactions of $\mathrm{Y}_{3} \mathrm{Fe}_{5-x} \mathrm{Al}_{x} \mathrm{O}_{12}(0.0 \leq x \leq 1.0)$ synthesized by solid state reaction was carried out. Mössbauer spectroscopy was used to investigate the effect of $\mathrm{Al}$ substitution on the hyperfine magnetic fields and on the site preferred by the $\mathrm{Al}^{3+}$ ions. In addition, X-ray diffraction (XRD), scanning electron microscope (SEM), and Vibrating Sample Magnetometer (VSM) were used to characterize all the samples to examine their structural and magnetic properties.

\section{Experimental Procedures}

$\mathrm{Y}_{3} \mathrm{Al}_{x} \mathrm{Fe}_{5-x} \mathrm{O}_{12}$ powders with $x=0.0,0.2,0.4,0.6,0.8$, and 1.0 were synthesized by solid state reaction method. Metallic oxides $\mathrm{Y}_{2} \mathrm{O}_{3}, \mathrm{Fe}_{2} \mathrm{O}_{3}$ and $\mathrm{Al}_{2} \mathrm{O}_{3}$ were used to prepare $\mathrm{Y}_{3} \mathrm{Al}_{x} \mathrm{Fe}_{5-x} \mathrm{O}_{12}$ powder samples. Appropriate weighted amounts of the metallic oxides were loaded into a hardened stainless-steel cup with ball to powder ratio of 10:1. The milling process was carried out at $250 \mathrm{rpm}$ for $16 \mathrm{~h}$. The resulting precursor was annealed at $1300^{\circ} \mathrm{C}$ for $2 \mathrm{~h}$. X-ray diffraction (XRD) patterns were collected using Philips $\mathrm{PW}$ $1720 \mathrm{X}$-ray diffractometer operating at $(40 \mathrm{kV}, 40 \mathrm{~mA})$, with $\mathrm{Cu}-\mathrm{K} \alpha$ radiation $(\lambda=1.5405 \AA)$. The samples were scanned over the angular range $15^{\circ}<2 \theta<75^{\circ}$ with $0.02^{\circ}$ scanning step and speed of $1 \mathrm{deg} / \mathrm{min}$. The XRD patterns were carried out using X'pert HighScore 2.0.1 software for phase identification, and Rietveld refinement of the crystal structure was performed using FullProf suite 2000 software.

The magnetic measurements at room temperature were performed using Vibrating Sample Magnetometer (VSM MicroMag 3900, Princeton Measurements Cooperation), providing a maximum applied magnetic field of $10 \mathrm{kOe}$. Room temperature (RT) Mössbauer spectra were collected over 1024 channels using a standard constant acceleration Mössbauer spectrometer, with a $50 \mathrm{mCi}^{57} \mathrm{Co}$ in a Rhodium matrix $\gamma$-ray source. The spectra were calibrated using room temperature Mössbauer spectrum of $\alpha$-Fe foil, and then analyzed using fitting routines based on least-squares analysis.

\section{Results and Discussion}

\subsection{XRD Analysis}

Figure 1 shows the powder XRD patterns of pure and $\mathrm{Al}$ substituted YIG with different Al concentrations $(x=0.0,0.2$, $0.4,0.6,0.8$, and 1.0). Rietveld analysis of all patterns was used to determine the refined crystal parameters of all pure and the Al substituted YIG samples. The analysis revealed the presence of a single garnet phase (space group cubic symmetry Ia-3d) without any impurity phase.

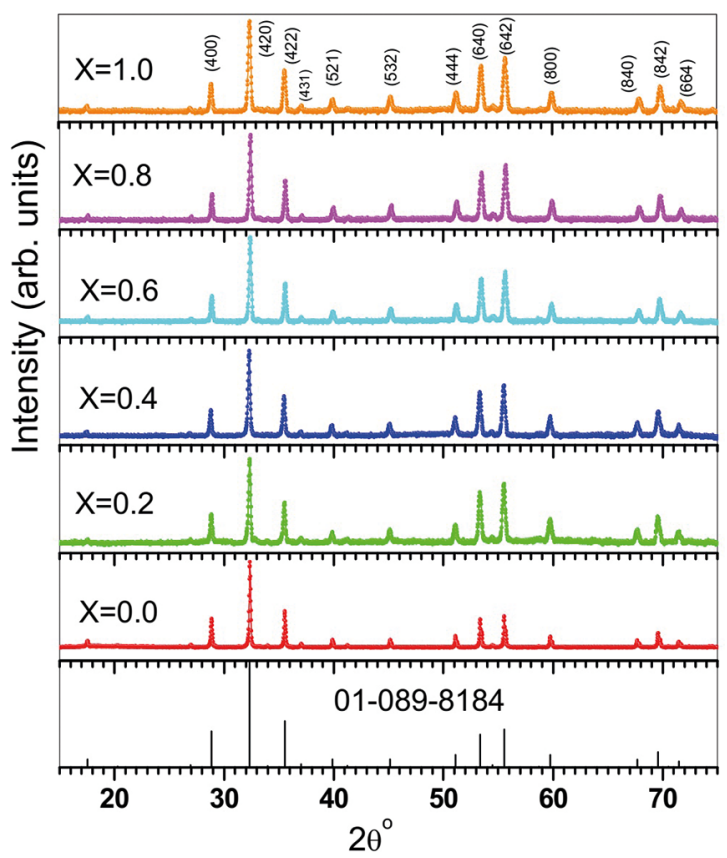

Figure 1. Powder X-ray diffraction patterns of $\mathrm{Y}_{3} \mathrm{Al}_{x} \mathrm{Fe}_{(5-x)} \mathrm{O}_{12}$ garnet samples.

Figure 2 shows representative Rietveld refined patterns for the samples with $x=0$ and 1 . The theoretical pattern (black continuous line) is in good agreement with the experimental data (red dots), where the residual difference curve (in blue) is a straight horizontal line with small ripples only around the main structural peak positions. The goodness- of-fit quality determined by the value of $\chi^{2}$, Bragg factor $\left(\mathrm{R}_{\mathrm{B}}\right)$, as well as the refined lattice parameter $a$ and unit cell volume $V$, and the $\mathrm{x}$-ray density for all samples are listed in Table 1 . The lattice constant and the cell volume decreased monotonically with increasing the concentration $x$ of the doped $\mathrm{Al}^{3+}$ ion. Such decrease can be attributed to the smaller ionic radius of $\mathrm{Al}^{3+}$ relative to that of $\mathrm{Fe}^{3+}$ in both the octahedral $(a)$ and tetrahedral $(d)$ sites, where the bond length $\mathrm{Al}^{3+}(a)-\mathrm{O}^{2-}=1.94 \AA$, 
whereas $\mathrm{Fe}^{3+}(a)-\mathrm{O}^{2-}=2.02 \AA$, and $\mathrm{Al}^{3+}(d)-\mathrm{O}^{2-}=1.76 \AA$, whereas $\mathrm{Fe}^{3+}(d)-\mathrm{O}^{2-}=1.87 \AA^{12}$. Also, the $\mathrm{x}$-ray density obtained from the refinement analysis exhibited a similar monotonic decrease with increasing $x$, contrary to what is expected as a result of the decrease of the cell volume. This is due to the fact that the rate of decrease of the molecular weight with Al-substitution is higher than the rate of decrease of the cell volume as $x$ increases. In addition, the observed broadening of the diffraction peaks for the Al-substituted YIG samples indicates that the substitution results in a poorer crystallinity of the YIG phase.

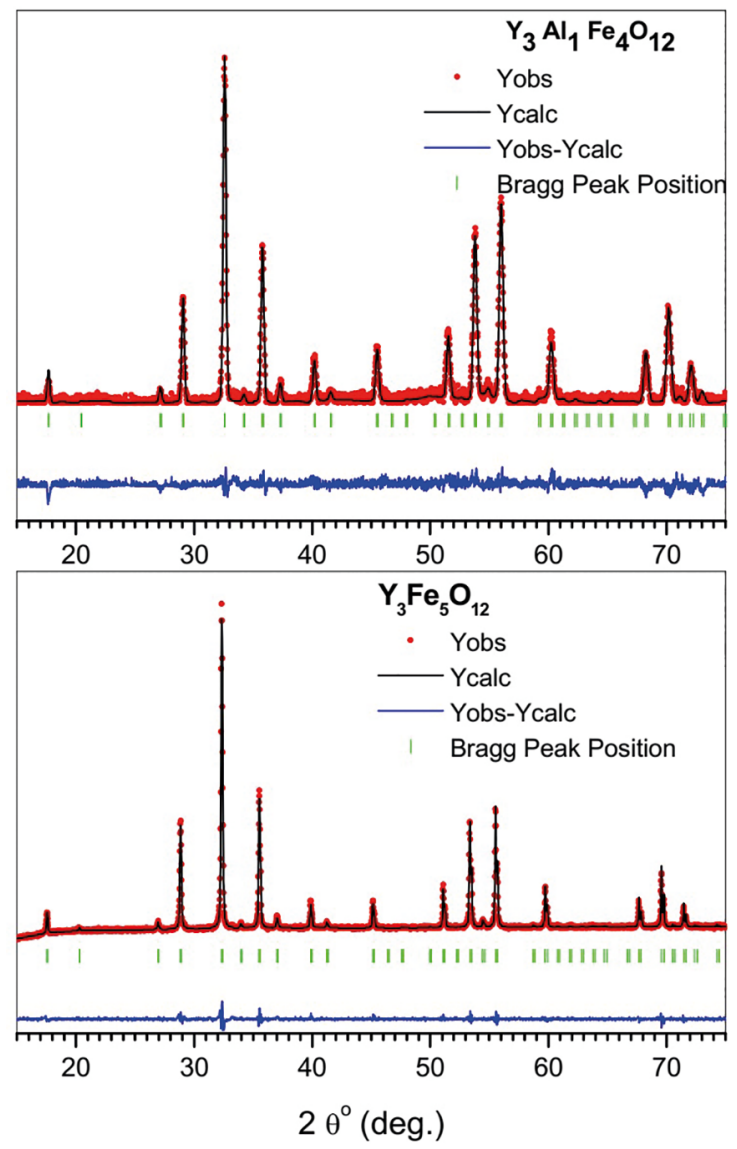

Figure 2. Refined XRD patterns for $\mathrm{Y}_{3} \mathrm{Al}_{x} \mathrm{Fe}_{(5-x)} \mathrm{O}_{12}$ garnet samples with $x=0$ and $x=1$. The residual difference $\left(\mathrm{Y}_{\mathrm{obs}}-\mathrm{Y}_{\text {calc }}\right)$ between the experimental $\left(\mathrm{Y}_{\mathrm{obs}}\right)$ and calculated data $\left(\mathrm{Y}_{\text {calc }}\right)$ is given in the lower part of the plots (blue line).

\subsection{SEM Analysis}

SEM images of pure YIG and Al doped YIG samples for different concentrations are shown in Figure 3. The figure indicates that all samples are composed of particles with irregular shapes and relatively narrow particle size distribution. As $x$ increased, however, the particle size became more uniform and exhibited a small reduction. Specifically, the sample with $x=0$ consisted of particles with size in the range from $\sim 0.8 \mu \mathrm{m}$ to $\sim 4 \mu \mathrm{m}$. The images of the samples with $x=0.2,0.4$, and 0.6 are generally similar to the image of the sample with $x=0$, but they revealed the presence of a larger fraction of smaller particles with size $\sim 1 \mu \mathrm{m}$, and an upper limit of particle size of nearly $3 \mu \mathrm{m}$. The SEM images of the samples with $x=0.8$, and 1.0 showed further reduction of particle size, and the particles became almost spherical in shape. The particle size distribution in these samples is narrower and more uniform, and the majority of particles are characterized by particle size $\leq 1 \mu \mathrm{m}$ in diameter. These results indicated that the $\mathrm{Al}$ substitution in YIG resulted in a small reduction of the particle size, uniform particle shape, and narrow particle size distribution.

\subsection{Magnetic Measurements}

The magnetic hysteresis loops at RT of $\mathrm{Y}_{3} \mathrm{Al}_{x} \mathrm{Fe}_{5-x} \mathrm{O}_{12}$ samples are shown in Figure 4. From the hysteresis loops, it can be noticed that all samples have negligible coercivity regardless of $\mathrm{Al}$ concentration $x^{20}$. This is indicative of the low RT crystal anisotropy of $\mathrm{YIG}^{21}$, and demonstrates that Al substitution has negligible effect on the crystal anisotropy.

That magnetization of all samples is almost saturated at an applied field of $10 \mathrm{kOe}$, and the saturation magnetization $\left(M_{\mathrm{s}}\right)$ was determined directly from the hysteresis loops and listed in Table 2. The saturation magnetization for the pure YIG sample is consistent with previously reported results ${ }^{3,21}$, and the saturation magnetization of the substituted samples decreased with the increase of $\mathrm{Al}^{3+}$ ions substituting $\mathrm{Fe}^{3+}$ ions at $(d)$ and $(a)$ sublattices. The monotonic decrease of $M_{\mathrm{s}}$ with increasing $x$ (Figure 5) can be attributed to the progressive reduction of the superexchange interactions between iron ions at $a$ and $d$ sites, and the reduction of the magnetic dipole-dipole interaction ${ }^{14,15}$. In an earlier investigation of the magnetic behavior of substituted garnets, it was proposed that the substitution of diamagnetic ions for $\mathrm{Fe}^{3+}$ ions at

Table 1. Bragg factor $\mathrm{R}_{\mathrm{B}}, \chi^{2}$, lattice constant $a$, unit cell volume, and density $\rho$ for all garnet samples.

\begin{tabular}{lccccc}
\hline Composition $(\boldsymbol{x})$ & $\chi^{2}$ & $\mathrm{R}_{\mathrm{B}}$ & $\mathrm{a}(\AA)$ & $\boldsymbol{V}(\AA)^{3}$ & $\boldsymbol{\rho}\left(\mathrm{g} / \mathrm{cm}^{3}\right)$ \\
\hline $\mathrm{Y}_{3} \mathrm{Fe}_{5} \mathrm{O}_{12}$ & 1.81 & 2.00 & $12.373(4)$ & 1894.4 & 5.175 \\
$\mathrm{Y}_{3} \mathrm{Fe}_{4.8} \mathrm{Al}_{0.2} \mathrm{O}_{12}$ & 1.44 & 2.40 & $12.336(8)$ & 1877.6 & 5.164 \\
$\mathrm{Y}_{3} \mathrm{Fe}_{4.6} \mathrm{Al}_{0.4} \mathrm{O}_{12}$ & 1.40 & 2.44 & $12.320(6)$ & 1870.2 & 5.144 \\
$\mathrm{Y}_{3} \mathrm{Fe}_{4.4} \mathrm{Al}_{0.6} \mathrm{O}_{12}$ & 1.49 & 2.23 & $12.308(1)$ & 1864.5 & 5.118 \\
$\mathrm{Y}_{3} \mathrm{Fe}_{4.2} \mathrm{Al}_{0.8} \mathrm{O}_{12}$ & 1.50 & 2.28 & $12.300(7)$ & 1861.2 & 5.086 \\
$\mathrm{Y}_{3} \mathrm{Fe}_{4} \mathrm{Al}_{1} \mathrm{O}_{12}$ & 1.32 & 2.89 & $12.287(9)$ & 1855.4 & 5.045 \\
\hline
\end{tabular}



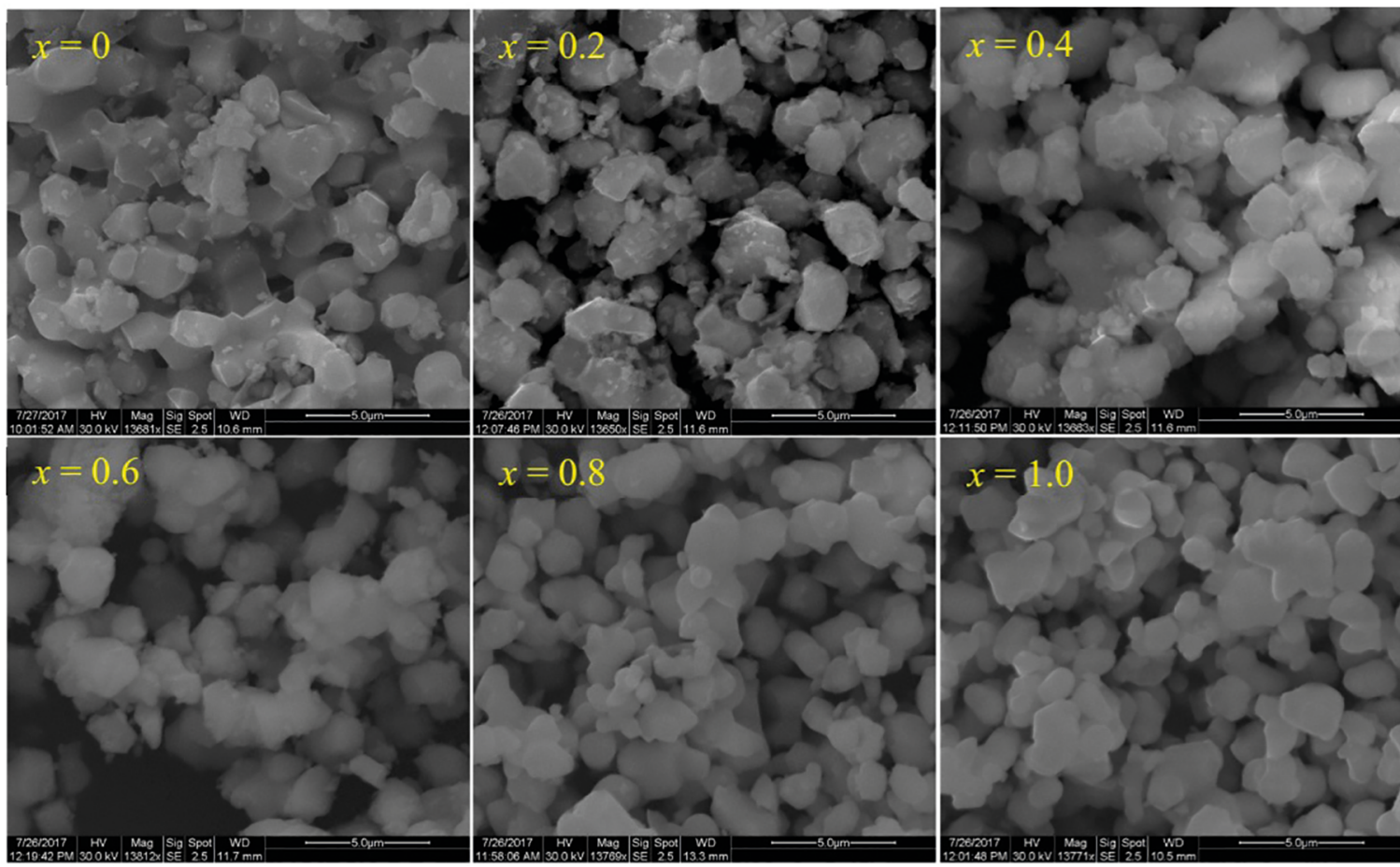

Figure 3. SEM images for all synthesized garnet samples.

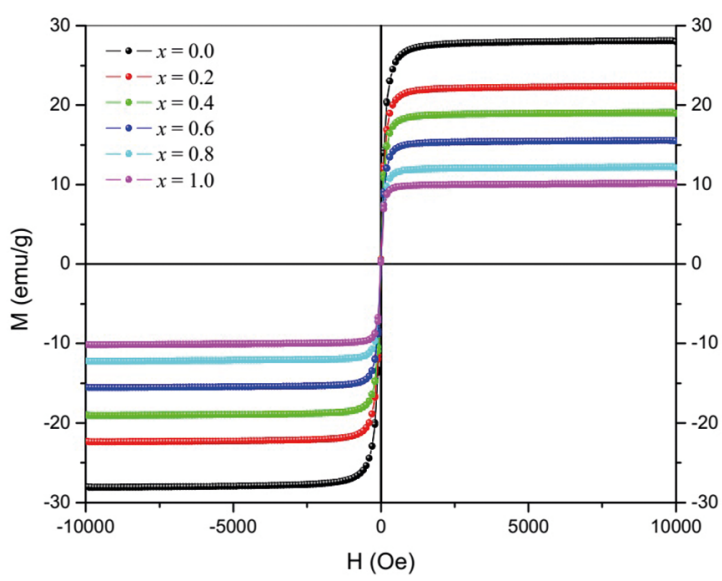

Figure 4. Magnetic hysteresis loops for $\mathrm{Y}_{3} \mathrm{Al}_{x} \mathrm{Fe}_{(5-x)} \mathrm{O}_{12}$ garnet samples.

a given sublattice leaves the moments of the $\mathrm{Fe}^{3+}$ ions in that sublattice in parallel alignment, while the consequent weakening of the $a$ - $d$ interactions leads to a more important role played by intra-sublattice interactions and randomization of the canting of the $\mathrm{Fe}^{3+}$ moments of the other sublattice ${ }^{22}$. This tendency occurs at low substitution levels, and as $x$ increases, the continued depletion of the iron sublattice by nonmagnetic ions reaches a point beyond which the intra-sublattice interactions become dominant over the $a$ - $d$ interactions ${ }^{3,22}$. These effects may explain the deterioration of the saturation magnetization of YIG with increasing the level of $\mathrm{Al}$ substitution for $\mathrm{Fe}$, where the magnetization behavior is dictated by the progressively increased importance of intra-sublattice interactions with increasing $x$.
Table 2. The saturation magnetization $\left(M_{\mathrm{s}}\right.$ in emu/g) for $\mathrm{Y}_{3} \mathrm{Al}_{x} \mathrm{Fe}_{5-x} \mathrm{O}_{12}$ garnet samples.

\begin{tabular}{ccccccc}
\hline$x$ & 0.0 & 0.2 & 0.4 & 0.6 & 0.8 & 1.0 \\
$M_{s}(\mathrm{emu} / \mathrm{g})$ & 28.0 & 22.3 & 19.0 & 15.5 & 12.1 & 10.1 \\
\hline
\end{tabular}

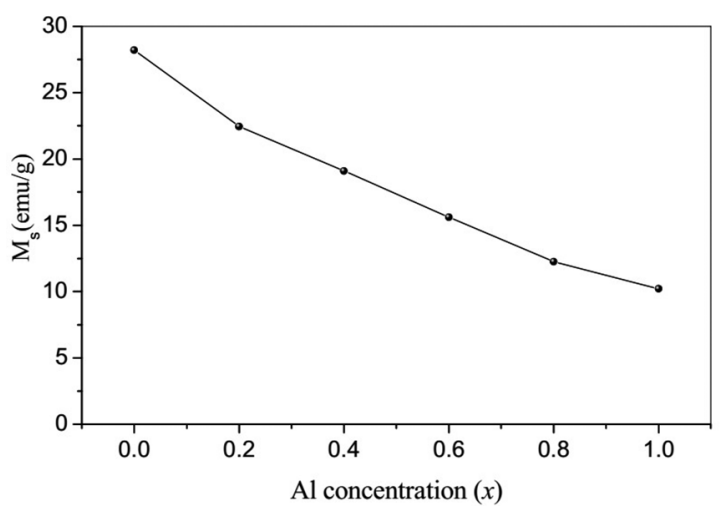

Figure 5. The saturation magnetization as a function of concentration for $\mathrm{Y}_{3} \mathrm{Al}_{x} \mathrm{Fe}_{(5-x)} \mathrm{O}_{12}$ garnet samples.

\subsection{Mössbauer spectroscopy}

Mössbauer spectroscopy was used to investigate the preferential site occupation of $\mathrm{Al}^{3+}$ ions in the garnet lattices. Accordingly, Mössbauer spectra (MS) of the system $\mathrm{Y}_{3} \mathrm{Al}_{x} \mathrm{Fe}_{5-x} \mathrm{O}_{12}$ with $x=0.0,0.2,0.4,0.6,0.8$, and 1.0 were recorded at room temperature (RT). Figure 6 shows the fitted Mössbauer spectra and the corresponding fitting parameters are listed in Table 3. 


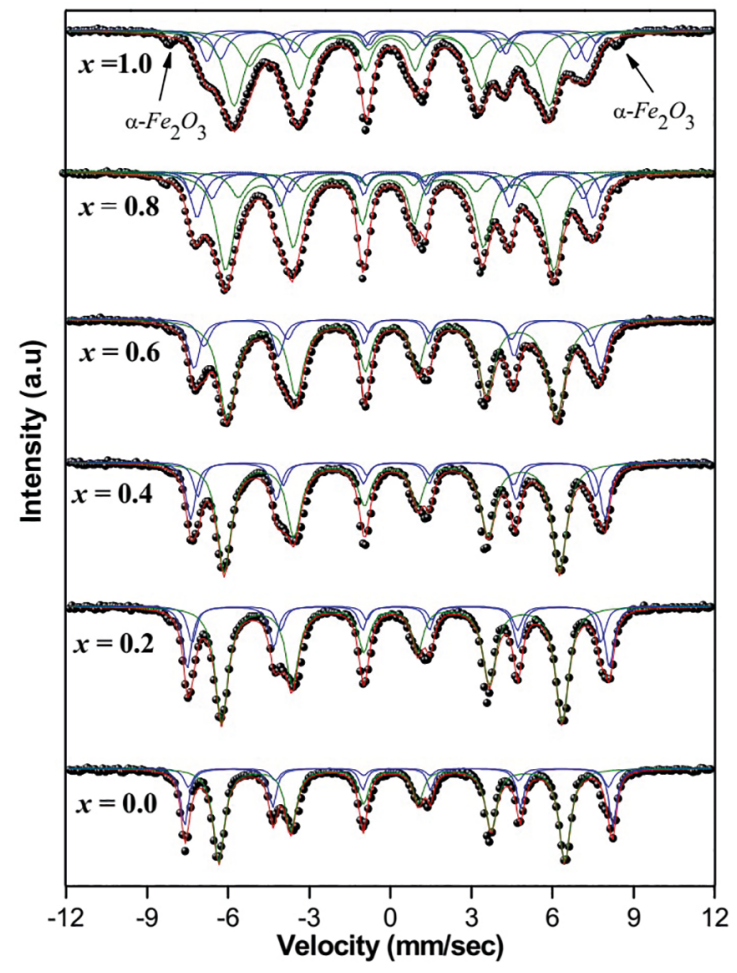

Figure 6. Mössbauer spectra for the $\mathrm{Y}_{3} \mathrm{Al}_{x} \mathrm{Fe}_{5-x} \mathrm{O}_{12}$ samples (filled circles) together with the theoretical spectrum obtained from the fitting software (continuous red line). The component corresponding to octahedral sites is represented by the blue sextet, while that corresponding to tetrahedral sites is represented by the green sextet

The spectrum of pure YIG $(x=0)$ was fitted with three magnetic sextets corresponding to iron ions $\left(\mathrm{Fe}^{3+}\right)$ in three different environments, two octahedral sites with $B_{h f}=497$ kOe and $487 \mathrm{kOe}$ and one tetrahedral site with $B_{h f}=401$ $\mathrm{kOe}^{23}$. The intensity ratio of $\% 37: \% 63$ for the two sublattices is close to $2: 3$, which is consistent with previously reported results $^{23-26}$.

The spectrum for the sample with $x=0.2$ was fitted also with three magnetic sextets as mentioned above. A reduction was observed in the values of the hyperfine magnetic field at the iron nucleus in both sublattices due to the substitution of $\mathrm{Al}^{3+} 20,27,28$. Specifically, the hyperfine fields associated with $\mathrm{Fe}^{3+}$ ions at octahedral sites reduced to $490 \mathrm{kOe}$ and $474 \mathrm{kOe}$, and that associated with $\mathrm{Fe}^{3+}$ ions at tetrahedral sites reduced to $395 \mathrm{kOe}$. Moreover, a little broadening in the line widths was observed for all components, resulting from the statistical distribution of nonmagnetic ions around the $\mathrm{Fe}^{3+}$ occupied sites.

Three magnetic components were also used to fit the Mössbauer spectra for the samples with $x=0.4$ and $x=0.6$. The hyperfine field values for all sites continue to decrease with increasing the concentration of $\mathrm{Al}^{3+}$ ions. This result is consistent with the drop in the saturation magnetization values compared to that of the pure YIG sample. The relative
Table 3. The hyperfine parameters and the percentage relative intensities $(I)$ obtained at room temperature for $\mathrm{Y}_{3} \mathrm{Al}_{x} \mathrm{Fe}_{5-x} \mathrm{O}_{12}$ garnet samples.

\begin{tabular}{|c|c|c|c|c|}
\hline Site & $\begin{array}{c}B_{h f} \\
(\mathrm{kOe})\end{array}$ & $\begin{array}{c}\mathrm{CS} \\
(\mathrm{mm} / \mathrm{sec}) \\
\pm 0.01\end{array}$ & $\begin{array}{c}\text { Width } \\
(\mathrm{mm} / \mathrm{sec}) \\
\pm 0.02\end{array}$ & $\begin{array}{l}I(\%) \\
\pm 1 \%\end{array}$ \\
\hline \multicolumn{5}{|c|}{$x=0.0$} \\
\hline \multirow{2}{*}{ Octahedral(s) } & 497 & 0.38 & 0.34 & 27 \\
\hline & 487 & 0.38 & 0.36 & 10 \\
\hline \multirow[t]{2}{*}{ Tetrahedral } & 401 & 0.15 & 0.50 & 63 \\
\hline & & $x=0.2$ & & \\
\hline \multirow{2}{*}{ Octahedral(s) } & 490 & 0.36 & 0.39 & 23 \\
\hline & 474 & 0.39 & 0.39 & 13 \\
\hline \multirow[t]{2}{*}{ Tetrahedral } & 395 & 0.15 & 0.58 & 64 \\
\hline & & $x=0.4$ & & \\
\hline \multirow{2}{*}{ Octahedral(s) } & 480 & 0.36 & 0.43 & 22 \\
\hline & 461 & 0.38 & 0.41 & 13 \\
\hline \multirow[t]{2}{*}{ Tetrahedral } & 389 & 0.15 & 0.63 & 65 \\
\hline & & $x=0.6$ & & \\
\hline \multirow{2}{*}{ Octahedral(s) } & 472 & 0.35 & 0.52 & 22 \\
\hline & 448 & 0.39 & 0.55 & 13 \\
\hline \multirow[t]{3}{*}{ Tetrahedral } & 382 & 0.16 & 0.79 & 65 \\
\hline & & $x=0.8$ & & \\
\hline & 468 & 0.35 & 0.40 & 5 \\
\hline \multirow[t]{2}{*}{ Octahedral(s) } & 450 & 0.37 & 0.55 & 18 \\
\hline & 422 & 0.44 & 0.59 & 11 \\
\hline \multirow{2}{*}{ Tetrahedral(s) } & 376 & 0.16 & 0.76 & 53 \\
\hline & 341 & 0.14 & 0.71 & 13 \\
\hline \multicolumn{5}{|c|}{$x=1.0$} \\
\hline \multirow{3}{*}{ Octahedral(s) } & 462 & 0.30 & 0.41 & 4 \\
\hline & 441 & 0.34 & 0.52 & 12 \\
\hline & 411 & 0.38 & 0.61 & 13 \\
\hline \multirow{2}{*}{ Tetrahedral(s) } & 366 & 0.13 & 0.84 & 47 \\
\hline & 327 & 0.11 & 0.90 & 24 \\
\hline
\end{tabular}

intensities of the octahedral and tetrahedral components suggest that $\mathrm{Al}^{3+}$ ions may replace the $\mathrm{Fe}^{3+}$ ions at the octahedral sites. This result can be also confirmed by the large broadening in the sextet of the tetrahedral site, which could be due to the local fluctuation of the chemical environment of this site arising from the substitution of $\mathrm{Al}^{3+}$ at the octahedral $\operatorname{sites}^{28}$.

The spectrum for the sample with $x=0.8$ was fitted with five magnetic components, three octahedral components with $B_{h f}=468 \mathrm{kOe}, 450 \mathrm{kOe}$, and $422 \mathrm{kOe}$ and two tetrahedral components with $B_{h f}=376 \mathrm{kOe}$ and $341 \mathrm{kOe}$ with intensity ratio of $\% 32: \% 68$. The evolution of the new component with $B_{h f}=422 \mathrm{kOe}$ could be attributed to Fe in the octahedral sites with $\mathrm{Al}$ in its environment which causes a reduction in $B_{h f}$ from about $500 \mathrm{kOe}$ down to this value. This also can be proven by observing the significant drop in the intensity that is 
associated with $B_{h f}=468 \mathrm{kOe}$. Moreover, a new component, with $B_{h f}=341 \mathrm{kOe}$, was observed, and could be associated with $\mathrm{Fe}^{3+}$ ions in tetrahedral sites surrounded with a chemical environment involving $\mathrm{Al}^{3+}$ ionic substitution for $\mathrm{Fe}^{3+}$ ions.

The spectrum for the sample with $x=1.0$ can be fitted as a superposition of five magnetic components as in the case for $x=0.80$, in addition to a weak magnetic component, with intensity less than $1 \%$, attributed to an $\alpha-\mathrm{Fe}_{2} \mathrm{O}_{3}$ phase. The fact that this phase was not detected by XRD is an indication that its fraction in the sample was below the delectability limit of the diffraction technique, and that Mössbauer spectroscopy is more sensitive to detecting traces of Fe-containing phases. The increase in the intensity, $71 \%$, and the line broadening of the tetrahedral components supports also the fact that $\mathrm{Al}^{3+}$ ions replaced $\mathrm{Fe}^{3+}$ ions in the octahedral sites. Moreover, the center shifts of the octahedral and tetrahedral sites show some decrease. This can be attributed also to the local fluctuation of the chemical environment induced by the statistical distribution of $\mathrm{Al}^{3+}$ ions in the garnet lattice.

\section{Conclusions}

The $\mathrm{Y}_{3} \mathrm{Al}_{x} \mathrm{Fe}_{5-x} \mathrm{O}_{12}$ garnets with $\mathrm{I} a 3 \mathrm{~d}$ space group were been prepared by solid state reaction and. The lattice constant was found to decrease with increasing $\mathrm{Al}^{3+}$ concentration. The substitution of $\mathrm{Fe}^{3+}$ by $\mathrm{Al}^{3+}$ at octahedral sites was confirmed by Mössbauer spectroscopy. The distribution of $\mathrm{Al}^{3+}$ ions among octahedral and tetrahedral sites, contrary to the reported preference for tetrahedral sites, may indicate the sensitivity of the ionic distribution to the preparation procedure and heat treatment, in agreement with the results of Cohen and Chegwidden (1966). Moreover, the saturation magnetization $M_{\mathrm{s}}$ decreased with the increase of the concentration of $\mathrm{Al}^{3+}$ ions due to the weakening of the superexchange interactions between the $\mathrm{Fe}^{3+}$ ions induced by the depletion of the $\mathrm{Fe}$ sublattices by nonmagnetic $\mathrm{Al}^{3+}$ substitution.

\section{References}

1. Bertaut F, Forrat F. Structure des ferrites ferrimagnetiques des terres rares. Comptes Rendus de l'Academie des Sciences. 1956;242:382-384.

2. Mahmood SH. Permanent Magnet Applications. In: Mahmood $\mathrm{SH}$, Abu-Aljarayesh I, eds. Hexaferrite Permanent Magnetic Material. Millersville: Materials Research Forum LLC; 2016. p. 153-165.

3. Gilleo MA. Ferromagnetic insulators: Garnets. In: Wohlfarth PE, ed. Ferromagnetic Materials: a Handbook on the Properties of Magnetically Ordered Substances, Volume 2. Amsterdam: North-Holland; 1980. p. 1-53.

4. Paoletti A. Physics of Magnetic Garnet. In: Proceedings of the International School of Physics "Enrico Fermi"; Course LXX; 1977 Jun 27- Jul 9; Varenna on Lake Como, Villa Monastero, Italy. Amsterdam: North Holland; 1978.
5. Jha AR. Rare Earth Materials: Properties and Applications. Boca Raton: CRC Press; 2014.

6. Lataifeh MS. Room temperature magnetization measurements of some substituted rare earth iron garnets. Applied Physics A. 2008;92(3):681-685.

7. $\mathrm{Xu} \mathrm{H}$, Yang $\mathrm{H}, \mathrm{Xu}$ W, Yu L. Magnetic properties of Bi-doped $\mathrm{Y}_{3} \mathrm{Fe}_{5} \mathrm{O}_{12}$ nanoparticles. Current Applied Physics. 2008;8(1):1-5.

8. Eschenfelder A. Crystalline films for bubbles. In: Wohlfarth PE, ed. Ferromagnetic Materials: a Handbook on the Properties of Magnetically Ordered Substances, Volume 2. Amsterdam: North-Holland; 1980. p. 297-343.

9. Gilleo M, Geller S. Substitution for Iron in Ferrimagnetic YttriumIron Garnet. Journal of Applied Physics. 1958;29(3):380-381.

10. Gilleo M, Geller S. Magnetic and Crystallographic Properties of Substituted Yttrium-Iron Garnet. $3 \mathrm{Y}_{2} \mathrm{O}_{3} \cdot x \mathrm{M}_{2} \mathrm{O}_{3} \cdot(5-x) \mathrm{Fe}_{2} \mathrm{O}_{3}$. Physical Review. 1958;110(1):73-78.

11. Geller S, Williams HJ, Espinosa GP, Sherwood RC. Importance of Intrasublattice Magnetic Interactions and of Substitutional Ion Type in the Behavior of Substituted Yttrium Iron Garnets. Bell Labs Technical Journal. 1964;43(2):565-623.

12. Geller S. Crystal chemistry of the garnets. Zeitschrift für Kristallographie-Crystalline Materials. 1967;125:1-47.

13. Cohen HM, Chegwidden RA. Control of the Electromagnetic Properties of the Polycrystalline Garnet $\mathrm{Y}_{3} \mathrm{Fe}_{3.75} \mathrm{Al}_{1.25} \mathrm{O}_{12}$. Journal of Applied Physics. 1966;37(3):1081-1082.

14. Kim CS, Min BK, Kim SJ, Yoon SR, Uhm YR. Crystallographic and magnetic properties of $\mathrm{Y}_{3} \mathrm{Fe}_{5-x} \mathrm{Al}_{x} \mathrm{O}_{12}$. Journal of Magnetism and Magnetic Materials. 2003;254-255:553-555.

15. Thongmee $\mathrm{S}$, Winotai $\mathrm{P}$, Tang IM. Local field fluctuations in the substituted aluminum iron garnets, $\mathrm{Y}_{3} \mathrm{Fe}_{5-x} \mathrm{Al}_{x} \mathrm{O}_{12}$. Solid State Communications. 1999;109(7):471-476.

16. Motlagh ZA, Mozaffari M, Amighian J, Lehlooh AF, Awawdeh $\mathrm{M}$, Mahmood S. Mössbauer studies of $\mathrm{Y}_{3} \mathrm{Fe}_{5-x} \mathrm{Al}_{x} \mathrm{O}_{12}$ nanopowders prepared by mechanochemical method. Hyperfine Interactions. 2010;198(1-3):295-302.

17. Kim CS, Min BK, An SY, Uhm YR. Mössbauer studies of $\mathrm{Y}_{3} \mathrm{Fe}_{475} \mathrm{Al}_{025} \mathrm{O}_{12}$. Journal of Magnetism and Magnetic Materials. 2002;239(1-3):54-56.

18. Garskaite E, Gibson K, Leleckaite A, Glaser J, Niznansky $\mathrm{D}$, Kareiva A, et al. On the synthesis and characterization of iron-containing garnets $\left(\mathrm{Y}_{3} \mathrm{Fe}_{5} \mathrm{O}_{12}, \mathrm{YIG}\right.$ and $\left.\mathrm{Fe}_{3} \mathrm{Al}_{5} \mathrm{O}_{12}, \mathrm{IAG}\right)$. Chemical Physics. 2006;323(2-3):204-210.

19. Rodic D, Mitric M, Tellgren R, Rundlof H. The cation distribution and magnetic structure of $\mathrm{Y}_{3} \mathrm{Fe}_{(5-x)} \mathrm{Al}_{x} \mathrm{O}_{12}$. Journal of Magnetism and Magnetic Materials. 2001;232(1-2):1-8.

20. Bouziane K, Yousif A, Widatallah HM, Amighian J. Site occupancy and magnetic study of $\mathrm{Al}^{3+}$ and $\mathrm{Cr}^{3+}$ co-substituted $\mathrm{Y}_{3} \mathrm{Fe}_{5} \mathrm{O}_{12}$. Journal of Magnetism and Magnetic Materials. 2008;320(19):2330-2334.

21. Smit J, Wijn HPJ. Ferrites. Eindhoven: Philips Technical Library; 1959

22. Geller S. Magnetic Behavior of Substituted Ferrimagnetic Garnets. Journal of Applied Physics. 1966;37(3):1408-1414. 
23. Mohaidat QI, Lataifeh M, Mahmood SH, Bsoul I, Awawdeh M. Structural, Mössbauer Effect, Magnetic, and Thermal Properties of Gadolinium Erbium Iron Garnet System $\mathrm{Gd}_{3}$ ${ }_{x} \mathrm{Er}_{x} \mathrm{Fe}_{5} \mathrm{O}_{12}$. Journal of Superconductivity and Novel Magnetism. 2017;30(8):2135-2141.

24. Lataifeh MS, Lehlooh AFD. Mossbauer spectroscopy study of substituted yttrium iron garnets. Solid State Communications. 1996;97(9):805-807.

25. Lataifeh MS, Lehlooh AFD, Mahmood S. Mössbauer spectroscopy of Al substituted $\mathrm{Fe}$ in holmium iron garnet. Hyperfine Interactions. 1999;122(3-4):253-258.
26. Lataifeh MS, Mahmood S, Thomas MF. Mössbauer spectroscopy study of substituted rare-earth iron garnets at low temperature. Physica B: Condensed Matter. 2002;321(1-4):143-148.

27. Murumkar VD, Shengule DR, Bichile GK, Jadhav KM. Mössbauer study of $\mathrm{Al}$ and $\mathrm{Cr}$ co-substituted Yttrium iron garnets. Hyperfine Interactions. 2009;192(1-3):93-100.

28. Lehlooh AF, Mahmood S, Mozaffari M, Amighian J. Mössbauer Spectroscopy Study on the Effect of Al-Cr Co-Substitution in Yttrium and Yttrium-Gadolinium Iron Garnets. Hyperfine Interactions. 2004;156(1-4):181-185. 